\title{
Las Políticas de Gasto Europeas y el Desarrollo Económico*
}

\author{
Isabel Vega Mocoroa
}

El objeto de este artículo es el estudio del desarrollo económico en la Unión Europea a través de los instrumentos que existen para su consecución, es decir las diversas políticas comunitarias de gastos... Las perspectivas financieras, marco financiero plurianual de la UE, garantizan una evolución armónica y controlada de las grandes categorias de gastos, y por lo tanto aseguran el desarrollo de aquellas politicas ligadas al Acta Única. Entre dichas categorias de gastos podemos distinguir dos cuyo destino son las distintas actuaciones relacionadas con el desarrollo económico y que anualmente se materializaran en dos rúbricas distintas de Gastos en el presupuesto CE, éstas son: las acciones estructurales $y$ las acciones exteriores, o dicho de otra forma política de gastos cuya finalidad es el desarrollo interno de la comunidad, $y$ política de gastos cuyo objetivo principal es el de contribuir al desarrollo económico de países terceros o países no miembros. Estas dos vías para conseguir el desarrollo, corresponden a dos concepciones distintas del objetivo del desarrollo económico: externo e intemo cuyo marco institucional y vías de canalización son distintas.

\section{Introducción}

El objeto de este artículo como su título indica, es el estudio del desarrollo económico en la Unión Europea a través de los instrumentos que existen para su consecución, es decir las diversas políticas comunitarias de gastos. No vamos a entrar en el debate sobre lo que son políticas comunes y simples líneas de gastos comunitarias; cuando hablamos en términos generales de políticas de gasto nos referimos a líneas de actuación comunitaria con dotación presupuestaria (el presupuesto general $\mathrm{CE}$ ). Las perspectivas financieras, marco financiero plurianual de la UE, garantizan una evolución armónica y controlada de las grandes categorías de gastos, y por lo tanto aseguran el desarrollo de aquellas políticas ligadas al Acta Única, entre dichas categorías de gastos podemos distinguir dos cuyo destino son las distintas actuaciones relacionadas con el desarrollo económico y que anualmente se materializarán en dos rúbri-

- Este artículo refieja únicamente la opinión del autor y no compromete en absoluto la posición de la Comisión Europea. 

bles, los planteamiento comunitarios al enfrentarse al problema del desarrollo exterior cada vez se acercan más a posturas heterodoxas, que parten del supuesto de la inflexibilidad de las economías de estos países, tal y como se desprende de las actividades que desarrollan en el marco de la política de cooperación al desarrollo. Este enfoque "externo" del desarrollo tiene su fundamento jurídico en el marco del Tratado de Roma y las modificaciones que éste ha sufrido posteriormente a través de los nuevos Tratados comunitarios son fiel reflejo de la evolución de este objetivo en el contexto europeo así como de la reorientación de sus instrumentos; es por ello que antes de iniciar el estudio de las vías de actuación de la UE en favor del desarrollo exterior vamos a detenernos en el análisis del marco institucional.

\subsection{Marco institucional: Fundamentos jurídicos}

La inclusión de este apartado está justificada, si retomando planteamientos de la economía institucionalista, consideramos que las normas como "instituciones" tienen un valor importante en la consecución de los objetivos económicos, pues establecen las pautas de juego y crean las condiciones necesarias para la evolución y desarrollo del mismo. En el caso que nos ocupa del desarrollo económico externo el Tratado de Roma de 1957 en su original art. 3K incluía como instrumento para la consecución de los objetivos generales de la Comunidad recogidos en el art. 2, "La asociación de los países y territorios de ultramar, a fin de incrementar los intercambios y promover en común el desarrollo económico y social", este artículo en la actualidad se ha desdoblado en los actuales arts. 3Q "una política en el ámbito de la cooperación al desarrollo" y al $3 \mathrm{R}$ "Ia asociación de los países y territorios de ultramar con el fin de incrementar los intercambios y continuar en común el esfuerzo por el desarrollo económico y social". En relación con este desdoblamiento podemos hablar de una primera vía de desarrollo a través de la política comercial y de los intercambios comerciales que tendrá su desarrollo jurídico en los art. 113, 131-136 y 238 y de una segunda vía a través de una política de cooperación al desarrollo que se regulará por una serie de normas propias art. 130U-130Y del TCE.

\subsection{Diversas vías de canalizar la ayuda al desarrollo}

Entre la política comercial y la cooperación al desarrollo propiamente dicha hay una estrecha relación y es que en ambos casos se trata de 
relaciones de la UE con el exterior, relaciones que tienen un fuerte componente histórico-geográfico que determinará el distinto grado o nivel de relación entre la UE y ciertos países terceros.

\section{A) Actividades en el marco de la política comercial}

La política comercial comunitaria es consustancial al nacimiento de la Unión aduanera, ya que la existencia de una arancel común frente a terceros Estados, junto con la existencia de un régimen general de importaciones y exportaciones de la comunidad frente a terceros garantizan y de otras medidas tales como las antidumping o el cumplimiento con las propias normas de defensa comercial del antiguo GATT, hoy en día OMC, constituyen los principales elementos de la política comercial comunitaria. El último elemento de esta política esta directamente relacionado con las reivindicaciones realizadas por los Países menos avanzados, en adelante PMA, en materia comercial y desarrollo económico, nos referimos al Sistema de Preferencias Generalizadas SPG en principio podía pensarse que se trata de un elemento que contradice los principios generales del antiguo GATT en lo relativo a la aplicación de la cláusula de la nación más favorecida NMF, ya que consiste en otorgar por parte de la UE una serie de beneficios arancelarios para ciertos productos procedentes de los países en vías de desarrollo. El SPG fue concebido en el seno de la UNCTAD como excepción a la cláusula de la NMF o principio de no discriminación y como vehículo de industrialización a los países en desarrollo, el GATT mediante una cláusula de habilitación permitió a los países CE la aplicación del SPG en su política comercial común. El Sistema de Preferencias Generalizadas se convirtió de este modo en un instrumento propio de la política comercial comunitaria pero al mismo tiempo en un instrumento al servicio del desarrollo económico, pues su razón de ser se encuentra justamente en favorecer el desarrollo industrial de los PMA, permitiendo que la mayor parte de los productos manufacturados y semifacturados de dichos países estén sujetos a una exención o rebaja arancelaria pudiendo establecer en su caso contingentes, de tal forma que encuentren salida en el mercado comunitario en condiciones similares a las de los mismos productos de origen comunitario y ello actuase como un factor determinante para que dichos países se industrialicen. Este sistema no se aplica de forma general a todos los productos que provienen de países terceros, quedando excluidos los productos agrícolas de base, alejados de la política industrial de los países en vías de desarrollo. Para concluir hemos de aclarar 
que aunque la condición se aplica de forma general a todos los países en vías de desarrollo, la misma quedará excluida cuando alguno de estos países disfrute de un acuerdo aún más beneficioso en atención a algún convenio bilateral más beneficioso; este sistema ha de ser renovado cada año.

En el marco de la política comercial existen una serie de acuerdos regionales o bilaterales entre la UE y distintas áreas geográficas, así como otra serie de acuerdos comerciales de carácter multilateral o general como lo son los acuerdos multifibras, por ejemplo. En relación con el primer tipo de acuerdos comerciales, su clasificación puede atender a dos criterios uno de tipo geográfico y otro, en atención al carácter preferencial o no preferencial de los mismos.

\begin{tabular}{|c|c|c|}
\hline ÁREA & ACUERDO PREFERENCIAL & ACUERDO NO PREFERENCIAL \\
\hline EFTA & $\begin{array}{l}\text { Espacio Económico Europeo } \\
\text { (zona de libre cambjo) }\end{array}$ & \\
\hline $\begin{array}{l}\text { Antiguo COMECOM: } \\
\text { NEI+PECO }\end{array}$ & \begin{tabular}{|l|} 
Acuerdos preferenciales con \\
alguno de estos países (v.gr \\
PECO), con el objetivo de \\
permititles participar en el proceso \\
de integración europea (ampliación \\
hacia el Este), creación del BERD y \\
otros programas especificos de la \\
UE
\end{tabular} & \\
\hline Paises ACP & $\begin{array}{l}\text { Acuerdos de LOME } \\
\text { Preferencias Arancelarias } \\
\text { Unilaterales, SYSMIN, STABEX, } \\
\text { actuaciones del BEl, creación del } \\
\text { FED }\end{array}$ & \\
\hline Países mediterráneos & $\begin{array}{l}\text { Relaciones privilegiadas de } \\
\text { cooperación y asociación por } \\
\text { razones culturales, históricas y } \\
\text { geográficas. Paises del Magreb y } \\
\text { del Mashreq. Política mediterránea } \\
\text { de la Comunidad y Política } \\
\text { Mediterránea Renovada. } \\
\text { Preferencias arancelarias y } \\
\text { cooperación técnica y financiera. }\end{array}$ & \\
\hline Latinoamérica & & $\begin{array}{l}\text { Acuerdos comerciales } \\
\text { multilaterales SPG, acuerdos } \\
\text { bilaterales y con carácter temporal, } \\
\text { algunos paises tienen dentro del } \\
\text { sistema un régimen especial. } \\
\text { También acuerdos de cooperaciön, } \\
1995 \text { acuerdo con el Mercosur }\end{array}$ \\
\hline Asia & & $\begin{array}{l}\text { Se trata de acuerdos comerciales, } \\
\text { que aplican en aquellos países en } \\
\text { vía de desarrollo industrial el SPG, } \\
\text { pero no acuerdos preferenciales } \\
\text { más beneficiosos. }\end{array}$ \\
\hline $\begin{array}{l}\text { Otros países } \\
\text { Desarrollados }\end{array}$ & & $\begin{array}{l}\text { Acuerdos comerciales } \\
\text { multilaterales sobre las bases de la } \\
\text { OMC, y en algún caso acuerdos } \\
\text { bilaterales sectoriales }\end{array}$ \\
\hline
\end{tabular}


La política de desarrollo exterior de la UE incluye dos tipos de instrumentos los de carácter comercial que estamos analizando y los instrumentos de cooperación; aunque ambos instrumentos están estrechamente relacionados, pues la mayor parte de estas áreas geográficas que tienen vínculos comerciales con la UE también son beneficiarias de algún tipo de ayuda alimentaria o de carácter financiero, en este apartado, vamos a centrarnos en las relaciones exclusivamente de carácter comercial que favorecen el desarrollo. A la vista del cuadro sipnoptico resumen de las relaciones comerciales de la UE, deducimos que en atención al grado de intensidad de los acuerdos comerciales aquellos que mayores efectos positivos favorables al comercio pueden aportar serán aquellos de carácter preferencial destinados a zonas integradas con países en vías de desarrollo o por llamarlos de otro modo países menos avanzados PMA, es por ello que merecen estudio especial las relaciones UE-ACP conocidos como los acuerdos de LOME.

\section{a) Los acuerdos comerciales preferenciales con los países}

\section{ACP -África, Caribe y Pacífico}

El origen jurídico de estos acuerdos tan especiales de la UE con los países ACP se encuentra en el art. 131 TCE y los objetivos de los mismos en los arts 132-136. El Tratado de Roma había previsto la posibilidad de establecer "un régimen de asociación entre la Comunidad y aquellos países y territorios no europeos que mantienen relaciones especiales con Bélgica, Dinamarca, Francia, Países Bajos y Reino Unido", el sentido de este artículo hemos de entenderlo en su contexto histórico geográfico, ya que cuando se formó la CEE, algunos de sus Estados miembros tenían colonias en Africa y otros continentes, aunque en el momento actual la situación es bien diferente y se trata de estados independientes, en el convenio de Yaunde 1963 se estableció un acuerdo de carácter preferencial entre los estados CE y la mayoría de sus ex-colonias con el fin mantener una relaciones especiales de carácter comercial y de cooperación; estos acuerdos se extendieron a países que no habían sido ex-colonias $\mathrm{CE}$ aunque geográficamente se situaban en Africa, Caribe o el Pacífico. Con la primera ampliación, nuevos estados ex-colonias británicas en el área desean beneficiarse de estos acuerdos y en 1975 se firman los acuerdos de LOME I; desde entonces, hasta el momento actual: acuerdos de LOME IV, el número de estados beneficiados ha pasado de 46 a 70 . Las ventajas más destacadas de estos acuerdos podemos agruparlas en tres puntos: 1) rela- 
ciones comerciales preferenciales con la UE, 2) mecanismos de garantías específicos y 3) cooperación financiera y técnica; sólo los dos primeros mecanismos corresponderían a prácticas enmarcadas en las relaciones de carácter estrictamente comercial, pero los tres, sin embargo, tratan de estimular el desarrollo de los países ACP. Aunque se han tratado de justificar las relaciones UE-ACP por razones histórico culturales, en honor a la verdad hemos de coincidir con (Ahijado M., 1998), que existe un juego de complementariedades positivas, pues Europa está interesada en el mantenimiento de los ingresos por materias primas, así como en estabilizar las rentas de estos países, para que de este modo, los mismos mantengan sus compras a los productores europeos, contribuyendo así al sostenimiento de la demanda agregada. Vamos a analizar de forma breve los 3 mecanismos mencionados para de este modo conocer las ventajas que estos acuerdos suponen para el desarrollo de los países ACP.

En el marco de la política comercial, las preferencias concedidas por la UE a estos países consisten en la supresión de los derechos de aduana a la totalidad de las importaciones de productos industriales y agrícolas que provienen de estos países; esto supone que entre el 95 y el 98\% de la exportaciones de dichos países acceden libremente al mercado europeo, las únicas excepciones a este trato preferencial se aplican a ciertos productos agrícolas sujetos a exacciones o derechos agrícolas en el marco de la PAC ( Maillet P. y Rollet P., 1987), y a ciertos productos textiles sujetos al Acuerdo multifibras. Ventajas comerciales en las que no existe reciprocidad, ya que los países ACP sólo deberán garantizar a la UE el beneficio de la cláusula de la nación más favorecida. Los mecanismos de garantías específicas se refieren a la aplicación de ciertos "ajustes" cuya finalidad consiste en estabilizar básicamente los ingresos por exportación de ciertos productos agrícolas y mineros. En el primer caso se trata del sistema STABEX, que trata de garantizar los ingresos globales de los países ACP mediante préstamos sin interés o donaciones cuando los precios mundiales de 49 productos agrícolas de base, sufren fluctuaciones considerables de forma que hagan peligrar los ingresos globales de estos PMA dependientes de los mismos; estas transferencias se hacen con cargo al FED. El segundo sistema, denominado SYSMIN, presenta una técnica de ajuste distinta pues no consiste en compensar las pérdidas de ingresos por la exportación de productos mineros en este caso, sino en ayudar a la conservación del potencial de producción o de exportación de este sector, en espera de una coyuntura económica favorable; la mayor parte de estas ayudas proceden del BEI. 
Por último, en cuanto a los mecanismos de cooperación técnica y financiera, al tratarse de préstamos subvencionados del BEI y de donaciones y ayudas del FED que se encuentran al margen de las relaciones estrictamente de carácter comercial, serán objeto de estudio en el marco de los actividades de cooperación y desarrollo.

\section{b) Los acuerdos comerciales no preferenciales}

La política comercial de la Unión, cuyo objetivo viene fijado en el artículo 133 del Tratado: "contribuir, conforme al interés común, al desarrollo armonioso del comercio mundial, a la supresión progresiva de las restricciones a los intercambios internacionales y a la reducción de las barreras arancelarias" responde, tal y como se deduce del art. 2 del tratado, al objetivo de: "promover en el conjunto de la Comunidad un desarrollo armonioso, equilibrado y sostenible de las actividades económicas, un alto nivel de empleo y de protección social, la igualdad entre el hombre y la mujer, un crecimiento sostenible y no inflacionista, un alto grado de competitividad y de convergencia de los resultados económicos, un alto nivel de protección y de mejora de la calidad del medio ambiente, la elevación del nivel y de la calidad de vida, la cohesión económica y social y la solidaridad entre los Estados miembros. La política comercial, en sentido amplio, constituye, junto con la política monetaria y la política de desarrollo, el pilar principal de las relaciones económicas exteriores de la Unión Europea con el resto del mundo. Cubre los aspectos principales de los intercambios de bienes y servicios (barreras arancelarias y no arancelarias, defensa comercial, particularmente en caso de dumping y de subvenciones, créditos a la exportación), así como importantes aspectos relacionados con la propiedad intelectual, la inversión y la competencia.

Si los problemas comerciales se encuentran más frecuentemente identificados en el plano bilateral, su solución se busca en el ámbito más apropiado -multilateral, regional, o bilateral— según su naturaleza y las disposiciones jurídicas aplicables. La UE tiene especiales relaciones comerciales y de cooperación con el Mercosur basadas en un marco interregional de cooperación firmado el 15 de diciembre de 1995 y que ha entrado en vigor completamente el 1-7-1999, sin embargo Chile no forma parte del Mercosur, con el que se firmó un acuerdo en 1996 sobre la base de la fórmula $4+1$ y por lo tanto sólo aparece como asociado junto con Bolivia. Relaciones también de cierta importancia se establecen con México desde acuerdos de libre comercio con un trato similar al 
de los EE.UU. y Canadá, socios del mismo en la NAFTA (Noth America Free Trade Association). Para cerrar este capítulo dedicado a los otros acuerdos comerciales, a modo de ejemplo, vamos a analizar brevemente el caso de Chile con el que existe un acuerdo de cooperación bilateral firmado el 21 de junio de 1996 y en el que además de insistir en una serie de medidas destinadas a promover nuevas oportunidades para incrementar la competitividad en materia comercial, la investigación, las nuevas tecnologías, la asistencia a los sectores más pobres de la población y el desarrollo regional integrado de todo el país. Aunque en términos absolutos puede parecer que las relaciones comerciales CHILE-EU son poco importantes, si las situamos en el contexto global de los intercambios comerciales de la UE el resultado mejora. Ocupando el lugar 36 y 38 (del ranking de importaciones y exportaciones respectivamente) en las relaciones comerciales de la UE respecto al resto del mundo, y situándose en el $4^{\circ}$ lugar en Latinoamérica.

\section{Comercio EU en Meuros (1998)}

\begin{tabular}{|l|r|r|r|r|r|r|}
\hline Zona & $\begin{array}{l}\text { Importaciones } \\
\text { Ranking }\end{array}$ & Volumen & $\%$ & $\begin{array}{l}\text { Exportaciones } \\
\text { Ranking }\end{array}$ & \multicolumn{1}{l}{ Volumen } & \multicolumn{1}{l|}{} \\
\hline NAFTA $^{*}$ & & 176.831 & 22,9 & & 209.476 & 27,6 \\
\hline México & 34 & 4.026 & 0,6 & 21 & 9.282 & 1,3 \\
\hline AMLAT $^{*}$ & & 36.390 & 4,7 & & 45.556 & 6,0 \\
\hline Argentina & 35 & 4.559 & 0,6 & 28 & 6.355 & 0,8 \\
\hline Brasil & 15 & 12.915 & 1,7 & 13 & 14.176 & 1,9 \\
\hline Chile & 36 & 3.500 & 0,5 & 38 & 3.311 & 0,5 \\
\hline CEEC & & 92.251 & 12,0 & & 118,086 & 15,6 \\
\hline CIS & & 31.884 & 4,1 & & 20.880 & 2,8 \\
\hline MED & & 47.074 & 6,1 & & 69.045 & 9,1 \\
\hline A.ASEM & & 191.282 & 24,8 & & 96.782 & 12,8 \\
\hline
\end{tabular}

NAFTA: USA; Canadá y México.

AMLAT: 20 países de América Latina.

CEEC: Polonia, Hungría, Rumania, Bulgaria, Eslovenia, Estonia, Lituania, Letonia, R. Checa, Eslovaquia, Malta, Chipre y Turquía.

Al margen de los intercambios estrictamente comerciales y para completar la información sobre las relaciones de la EU con Chile, este país participa en los siguientes programas de cooperación exterior que 1a UE tiene establecidos con Latinoamérica: ALFA para los intercambios académicos, AL-INVEST destinado a la promoción de encuentros sectoriales entre operadores económicos y URBAN-AL dirigido a conseguir la mejora de las condiciones socioeconómicas y la calidad de vida de las poblaciones, así como el desarrollo equitativo de los 
centros urbanos entre la UE, sus regiones, ciudades y aglomeraciones y las de Latinoamérica.

\section{B) Actividades en el marco de la política de cooperación "al desarrollo"}

Aunque la UE viene ocupándose de labores relacionadas con la ayuda al desarrollo desde mediados de la década de los setenta, no cuenta con competencias propias en este terreno hasta la década de los noventa tras la aprobación del Tratado de Maastricht (arts. 130U-130Y). La política comunitaria en materia de cooperación al desarrollo ha de ser complementaria a las distintas políticas nacionales de desarrollo de los Estados miembros y tiene por finalidad favorecer el desarrollo económico y social de los países en desarrollo y en particular de los más desfavorecidos, la lucha contra la pobreza en los países en desarrollo y la inserción de estos últimos en la economía mundial. La Ayuda Oficial al Desarrollo de la UE tiene por objetivo el progreso económico y social de los países en desarrollo y cumple con los criterios de concesionalidad mínimos establecidos por el Comité de Ayuda al Desarrollo (CAD) de la OCDE, sus principales actuaciones se concentran en torno a tres núcleos: el primero podría definirse como cooperación al desarrollo en sentido estricto y engloba diversos tipo de actuaciones y proyectos que bajo el nombre de asistencia técnica incluyen a todos aquellos proyectos tradicionales de desarrollo (v.g. construcción de un hospital), y el envío de alimentos sin carácter de urgencia que se considera como ayudas alimentarias de carácter normal u ordinario (los productos ya pagados se colocan en los puertos CE, corriendo los gastos de transporte y distribución por cuenta del país beneficiario). El segundo bloque al que podríamos denominar de Ayuda Humanitaria incluye ayudas de diversa índole, ayuda alimentaria de urgencia, asistencia a refugiados y repatriados, ayudas para la lucha contra el SIDA, ayudas para paliar catástrofes y las consecuencias de los enfrentamientos armados y finalmente un tercer bloque que podríamos denominar de cooperación económica ya que agrupa las actividades de interés mutuo para los agentes económicos de los PMA y de los Estados EUR 15, como lo son las transferencias de tecnologías, los intercambios, y las inversiones directas.

\section{a) Instrumentos financieros para la cooperación económica}

En el estudio de las fuentes de financiación de la cooperación al desarrollo encontramos básicamente tres medios: uno presupuestario que 
se canalizaría a través de la rubrica 4 del presupuesto CE denominado acciones externas, y dos extrapresupuestarios, el Fondo Europeo de Desarrollo FED y el Banco Europeo de Inversiones (préstamos y acciones emprendidas por el BEI que tienen por finalidad contribuir al desarrollo económico).

\section{- El Fondo Europeo de Desarrollo. FED}

El FED juega un papel fundamental en la política de ayuda al desarrollo, sus gastos representan un $4 \%$ de los gastos del presupuesto $\mathrm{CE}$, y sus ingresos proceden de contribuciones financieras de los estados miembros. El FED tiene un régimen financiero autónomo del presupuesto general y ello responde a motivos de tipo político, ya que los Estados miembros se resisten a la pérdida del control directo sobre sus intervenciones como partes independientes de la Comunidad en las convenciones ACP; actualmente nos encontramos en el $8^{\circ} \mathrm{FED} 1995-2000$ relativo a la Convención de LOME IV, su función consiste básicamente en la concesión de subvenciones, ayudas, préstamos y operaciones de capital y riesgo a los países beneficiarios; sus recursos provienen de contribuciones financieras de los Estados según una clave de reparto que oscila entre un $26,06 \%$ de Alemania a un $0,19 \%$ de Luxemburgo pasando por un $6,6 \%$ en España, su gestión no responde al principio de anualidad como el presupuesto general y junto con su ejecución, ésta recae en la Comisión (D.G de Presupuestos y DG de Desarrollo) y de un Comité de representantes de los Estados Miembros. Anteriormente tuvimos ocasión de observar que en la política comercial CE respecto a los países ACP el FED intervenía a través de mecanismos de garantías específicos (STABEX y SYSMAN), sin embargo, el FED también se ha convertido en el principal instrumento financiero de cooperación ACP a través de las subvenciones para programas nacionales y regionales, la asignación de capital de riesgo, las denominadas ayudas de emergencia para casos de catástrofes, las ayudas a los refugiados y las bonificaciones de interés concedidas para los empréstitos suscritos con el BEI.

\section{- El Banco Europeo de Inversiones. BEI}

El BEI es el instrumento financiero más importante de carácter no presupuestario, fue creado en 1958 en virtud del antiguo art. 129 del TCEE con la misión de contribuir, recurriendo al mercado de capitales y a sus propios recursos, al desarrollo equilibrado y sin altibajos del mercado 
común en el interés de la Comunidad. A tal fin, el BEI facilitará mediante préstamos y garantías sin ánimo de lucro la financiación de proyectos en todos los sectores de la economía, (para la puesta en marcha las regiones menos desarrolladas, para intereses comunes a varios Estados o para la modernización de empresas o la creación de nuevas actividades). El BEI posee un estatuto de autonomía particular dentro de la Unión y unas instancias propias de decisión y control; sus recursos comprenden sus fondos propios (parte desembolsada de su capital, las reservas y las provisiones), los empréstitos y los recursos de la sección especial. Las modalidades de financiación a sus prestatarios consisten en prestamos individuales o globales y en una política de tipos de interés que incrementa en solo un $0,15 \%$ el coste de intervención en los mercados a efectos de cubrir únicamente los gastos de funcionamiento del Banco. El BEI constituye también la tercera fuente de financiación hacia los países en desarrollo ya que sus actuaciones como prestamista y garante de proyectos de inversión económicamente interesantes y acordes con los objetivos comunitarios se desdobla espacialmente en actuaciones en el ámbito interno -UE-y en el ámbito externo-Países no Miembros-; sus principales actuaciones en este segundo ámbito se encuadran dentro de la política comunitaria de cooperación y ayuda al desarrollo, resultando beneficiados de estas intervenciones 130 países terceros, pertenecientes a cuatro áreas geográficas distintas que tienen firmados acuerdos de cooperación con la Comunidad, éstas son: 1) los países Africa Caribe y Pacífico (ACP) en los que lleva interviniendo mediante la financiación de inversiones en agricultura, industria, servicios, pesca e infraestructuras desde hace más de 25 años, 2) los países de Europa Central y Oriental (PECO), en donde la contribución financiera del BEI se ha dedicado principalmente a las infraestructuras básicas de estos países y cuyas mayores realizaciones se han localizado en Bulgaria, Hungría, Polonia y la República Checa, 3) los países de la cuenca Mediterránea en los que el BEI promueve la realización de infraestructuras de transporte, telecomunicaciones y transferencia de energía, la gestión de los escasos recursos hídricos existentes y el desarrollo del sector privado productivo especialmente a través del nacimiento de joint ventures entre empresas locales y europeas, y finalmente, 4) los países de América Latina y de Asia que han firmado acuerdos de cooperación con la UE, en estos países las inversiones financiadas por el BEI han tenido por destino joint ventures con empresas de Estados miembros y proyectos energéticos. En el período temporal (1990-1994) las actuaciones del BEI en el ámbito interno han supuesto el $92 \%$ del importe total de sus financiaciones, des- 
tinándose el $8 \%$ restante a las actuaciones en el ámbito exterior donde se primaron aquellas realizadas en los países $\mathrm{PECO}$ y en la cuenca mediterránea. Los préstamos del BEI se considera que constituyen ayudas al desarrollo ya que tanto el FED como el presupuesto comunitario subvencionan o bonifican los tipos de interés del BEI que en principio se realizan a condiciones de mercado.

\section{- El presupuesto $C E$}

La ayuda financiera que a través del presupuesto CE se destina a la cooperación al desarrollo se incluye en las acciones exteriores que engloban tanto la ayuda humanitaria, la ayuda alimentaria, las ayudas destinadas a ONGs, las ayudas para la protección de los derechos humanos o las ayudas para los aspectos externos de ciertas políticas comunitarias como la mejora del medio ambiente, como aquellas otras ayudas de carácter "regional" que están destinadas a zonas geográficas concretas, como las destinadas a los países de la cuenca mediterránea, Latinoamérica, Asia y los países PECO. Las acciones externas vienen representando en los últimos años un volumen en torno al 6,6\%. del presupuesto $\mathrm{CE}$, se trata de la tercera línea de gasto presupuestario en atención a su cuantía, pero presentando gran diferencia con la PAC y la Política de Cohesión económica y social que representan respectivamente el 46 y $35 \%$ respectivamente del presupuesto $\mathrm{CE}$; el peso de las acciones externas en las perspectivas financieras está en torno al $6,4 \%$.

Como conclusión si quisiéramos cuantificar en cierto modo la política de cooperación al desarrollo de la UE en atención a sus fuentes y a los distintos destinos de sus medidas, podríamos hacerlo a través de una tabla resumen de cuanto hasta aquí hemos descrito junto con un mapa representativo del reparto de la ayuda comunitaria en el mundo.

Del estudio de la Tabla 1 adjunta, podemos destacar que cuantitativamente, en relación con los recursos del Presupuesto CE 1996, el total de ayudas a la cooperación económica es reducido (11\%); sin embargo, si procedemos a analizar los resultados de la cooperación económica en atención al destino geográfico de sus ayudas, del resultado de esta distribución espacial denotamos que el mayor interés actual se centra en los futuros socios de la UE (países PECO), que también existe una preferencia en lo relativo a la ayuda técnica y financiera con los países mediterráneos que sin duda responde a la política mediterránea de la UE y que las relaciones con los países ACP (70 Estados) a pesar de beneficiarse de los tres instrumentos de financiación y de ser los 
destinatarios del FED en exclusiva, poco a poco van perdiendo este trato preferencial que poseen en atención a antiguos lazos históricos con los primeros Estados CE. Si buscamos conocer el destino geográfico de la ayuda destinada a las zonas más desfavorecidas o a los PMA, éste sigue teniendo por principales destinatarios a los países ACP, aunque estos países no tengan un volumen comercial significativo con la UE, pues por ejemplo el volumen comercial de América Latina hacia la UE y viceversa es superior al de los estados ACP.

\section{TABLA 1}

\begin{tabular}{|c|c|c|c|c|}
\hline \multirow[b]{2}{*}{ MEDIDAS } & \multicolumn{4}{|c|}{$\begin{array}{l}\text { FUENTES DE FINANCIACIÓN DE LA } \\
\text { COOPERACIÓN ECONÓMICA (1996) en } \\
\text { Meuros }\end{array}$} \\
\hline & FED & BEI & $\begin{array}{l}\text { PRESPUESTO } \\
\text { CE }\end{array}$ & TOTAL \\
\hline AMEFICA LATINA & & 45,0 & 263,0 & 308,0 \\
\hline ASIA & & $\star \star \star$ & 406,5 & 406,5 \\
\hline $\mathrm{ACP}$ & ${ }^{*} 1.406,0$ & 395,5 & 150,0 & $1,951,5$ \\
\hline PAÍSES MEDITERRANEOS & & 681,0 & 688,0 & $1.369,0$ \\
\hline PECO+CEl & & $1.116,0$ & $\star \star \star 1.859,5,5$ & $2.976,0$ \\
\hline $\begin{array}{l}\text { AYUDA ALIMENTARIA Y } \\
\text { HUMANITARIA }\end{array}$ & & & 910,4 & 910,4 \\
\hline $\begin{array}{l}\text { ACCIONES GENERALES DE } \\
\text { COOPERACIÓN }\end{array}$ & & & 921,3 & $92 i, 3$ \\
\hline TOTAL & 1.406 & $2.192,5$ & $5.199,2$ & $8.797,7$ \\
\hline
\end{tabular}

* Incluimos todos los compromisos del FED sin diferenciar sus diferentes instrumentos

** El BEI agrupa América Latina y Asia

*** De donde 1.233,5 Meuros destinados a los países PECO

b) Importancia de la Cooperación de la UE al desarrollo en el entorno mundial

Como punto final a este breve estudio sobre la política de desarrollo exterior de la UE podemos concluir que a pesar del peso reducido de esta política en el conjunto de las políticas comunitarias, la UE de acuerdo con los datos de la OCDE es el mayor donante mundial de ayuda al desarrollo, y que sus porcentajes de contribución dentro del Comité de Ayuda al desarrollo se han estabilizado mientras que en los EE.UU. y Japón por el contrario han disminuido. Si tomamos como punto de referencia el Indice de esfuerzo de la ayuda al desarrollo (Ayuda Oficial al Desarrollo/PIB del donante) Europa seguiría situándose a la cabeza de los países donantes con un 0,43\%, frente al 0,22\% de los EE.UU. y al 0,32\% del Japón. 


\section{La Unión Europea y el desarrollo económico interno: La política de cohesión económica y social}

El segundo enfoque del objetivo del desarrollo económico en la UE tiene carácter interno, ajustándose a los objetivos generales del Tratado de Roma busca conseguir entre otras cosas "... un desarrollo armonioso y equilibrado de las actividades económicas en el conjunto de la comunidad...". Y será una política de gasto interior la encargada de su realización. La Política de Cohesión Económica y Social, en adelante PCES, tendrá por finalidad contribuir a la desaparición de las desigualdades regionales y promover un desarrollo armonioso del conjunto de la Comunidad reforzando la cohesión económica y social entre los Estados miembros; se trata, en definitiva de reducir las diferencias entre los niveles de desarrollo de las regiones europeas mediante una política de ayudas que permita a las regiones menos desarrolladas utilizando sus potencialidades, conseguir un mayor crecimiento económico que las conduzca a una convergencia real de sus economías respecto a las regiones más desarrolladas, de modo que las regiones menos favorecidas avancen relativamente más deprisa y así reduzcan la distancia que las separa de las más aventajadas. Si tuviéramos que definir lo que la Comunidad Europea entiende por cohesión podríamos decir que es "aquel grado social y políticamente aceptable de disparidad entre las diferentes regiones de la Comunidad Europea. No hay duda alguna de que Europa avanza cada día más en términos de eficiencia, y en contra a lo que los economistas de corte clásico esperaban del mercado como instrumento que llevaría a una reorganización de los recursos, y en fin a una disminución de las disparidades regionales (Padua Tomaso, 1985) la realidad ha sido bien diferente; a medida que se producían logros en materia de eficiencia y de crecimiento económico, las disparidades económicas entre las distintas regiones europeas aumentaban, las disparidades sociales no están bien vistas en ninguna sociedad avanzada como la UE y por lo tanto, el bienestar social aumentará si éstas desaparecen (Molle W., 1990). Por otra parte, la consecución de niveles de crecimiento y desarrollo adecuado en lo relativo a las regiones europeas contribuye a disminuir las disparidades intranacionales y contribuye en cierto modo al cumplimiento del objetivo de la redistribución a nivel agregado o supranacional (Remy Pru'homme, 1993). Como punto de partida de esta segunda parte del tema consideramos la existencia de una relación estrecha entre el desarrollo regional y la PCES como objetivo económico e instrumento a su servicio. 


\subsection{Marco institucional: Fundamentos jurídicos}

$\mathrm{El}$ art. 2 del TCE relativo a los objetivos generales de la Comunidad Europea, textualmente dice: "La Comunidad tendrá por misión promover; mediante el establecimiento de un mercado común y de una unión económica y monetaria mediante la realización de las políticas o acciones comunes contempladas en los artículos 3 y $3 \mathrm{~A}$, un desarrollo armonioso y equilibrado de las actividades económicas en el conjunto de la Comunidad, un crecimiento sostenible y no inflacionista que respete el medio ambiente, un alto grado de convergencia de los resultados económicos, un alto nivel de empleo y de protección social, la elevación del nivel y de la calidad de vida, la cohesión económica y social y la solidaridad entre los Estados Miembros." En el art. 3 se enumeran una lista no exhaustiva de instrumentos: políticas europeas, cuya finalidad no es otra que la de contribuir a la consecución de los objetivos enumerados en el art. 2, y en la misma encontramos el art. 3J relativo al fortalecimiento de la cohesión económica y social y el art. 3I relativo a la política social y al FSE. Sin embargo son los arts. $130^{\mathrm{a}} \mathrm{A}$ a $130 \mathrm{E}$ los que concretan los objetivos, contenido e instrumentos de la política de cohesión económica y social.

\subsection{Política de cohesión económica}

Cuando se habla de cohesión económica y social se habla de la política comunitaria que trata de reducir las diferencias entre los niveles de desarrollo de las distintas regiones europeas y el retraso de las regiones menos favorecidas; sin embargo, no debemos olvidar que las disparidades regionales y el desarrollo regional figuraban entre las prioridades comunitarias antes del nacimiento de la Política de cohesión Económica y Social, en adelante PCES como instrumento para su consecución.

\section{A) Antecedentes, elementos y principales líneas de reforma}

La cohesión económica y social tuvo su origen en el Acta Única Europea y su consolidación se debe al Tratado de Maastrich, Con anterioridad a dicha fecha y hasta 1975 en que se crea el Fondo de Desarro1lo Regional, en adelante FEDER, no se puede hablar propiamente ni tan siquiera de política regional comunitaria, sino de ciertos instrumentos con redistributivo, fundamentalmente de carácter social; estos eran: el Fondo Europeo de Orientación y Garantía Agrícola-Sección Orientación, en 
adelante FEOGA-O cuyo nacimiento data de 1962 y que desde 1989 se ha insertado en las acciones estructurales, el Fondo Social Europeo, en adelante FSE que se ocupa de la equidad social dentro de la política regional y que nace con el Tratado de Roma. Con la creación del FEDER, se puede decir que la Comunidad toma conciencia del problema de las disparidades regionales y por lo tanto podríamos pensar en la existencia de una incipiente política regional por sus instrumentos y escasos recursos, recordemos que al FEDER se destinaba inicialmente sólo el 5\% del Presupuesto CE. En esta primera fase existía una participación de todos los países miembros en las ayudas del FEDER, sin que pudiéramos realmente establecer una relación entre esas ayudas y las prioridades de política regional propiamente dicha; a partir de 1979, la dotación del FEDER se incrementa y además se crea una sección fuera de cuota, germen de una verdadera política regional común. La Reforma de 1989 ha marcado realmente la pauta de una verdadera política regional comunitaria bajo la forma de política de cohesión económica y social. Los objetivos del desarrollo regional y la disminución de disparidades interregionales en la CE. han quedado definitivamente ligados y el modelo de desarrollo adoptado para su concecución ha sido el de desarrollo endógeno, según se desprende del art. 3.1.c del reglamento marco CEE $\mathrm{N}^{\circ} 2052 / 88$ del Consejo de 24-8-1988, donde se incluían a las actividades que tengan por objeto el desarrollo del potencial endógeno de las regiones en las actuaciones del FEDER. Junto a los instrumentos mencionados al servicio de la PCES posteriormente han nacido otros como el IFOP, que en este nuevo período pasa de ser considerado como un instrumento financiero para la pesca a alcanzar la categoría de fondo estructural o el Fondo de cohesión a los que nos referiremos posteriormente.

La importancia del problema de las disparidades regionales en la UE y su relación con el desarrollo regional y su nuevo enfoque, han sido los causantes de la evolución que en materia de política regional se ha producido en la Unión Europea desde la reforma de 1988 y cuyas principales características han sido: 1) Cambio de una política compensatoria a través de subvenciones o transferencias de las regiones más ricas a las más pobres a una política cuya finalidad es el restablecimiento en las regiones menos desarrolladas de la eficiencia productiva a través del máximo aprovechamiento del potencial endógeno de las mismas. 2) Duplicidad de recursos, la importancia o agravación del problema había de ser combatida con un incremento de las ayudas a las regiones en dificultad, pero esta nueva medicina o receta se completaba también con una 
gama mayor de instrumentos específicos que se ajustaran mejor a las prioridades de cada región. Y 3) el diseño de todo un camino de programación tanto de los programas de desarrollo regional y su adecuación a las prioridades comunitarias, como de los circuitos financieros por los cuales se canalizan las ayudas europeas a una región concreta. Esta evolución del objetivo y de los instrumentos del desarrollo regional se ha materializado en tres reformas, situándonos en la actualidad en la tercera que corresponde al período 2000-2006: la primera está directamente relacionada con la aprobación del Acta Única y nace con la aprobación de los reglamentos 2052/88 y 4253/88-4256/88, y la segunda reforma que tiene su origen en los acuerdos de Maastricht y la creación del Fondo de Cohesión, se plasma el 20 de julio de 1993 en los seis reglamentos revisados que regulan los fondos estructurales para el período 1994-1999, reglamentos CEE 2081/93 y ss, ambas reformas coinciden aunque con pequeñas diferencias en lo fundamental, es decir en sus principios y modalidades de intervención. La tercera reforma insiste en la concentración de objetivos y prioridades reduciendo los objetivos de seis a tres y apuesta decididamente por PO plurifondos; que encuentra su respaldo legal en los reglamentos 1257/99, 1260/99 1263/99 1783/99 y 1784/99 (referencia al nuevo período según la Agenda 2000 en Tabla 2).

\section{B) Principios y modalidades de intervención}

De modo general vamos a revisar en que consisten estos principios:

a) Principio de concentración por el cual se concentran las ayudas europeas en torno a un número limitado de objetivos, de carácter espacial y no espacial en torno a los cuales podemos proceder a la clasificación de las distintas regiones o NUTS europeas; los fondos estructurales se concentran en torno a una serie de objetivos que oscilan entre 5 o 6 objetivos prioritarios (según el período en estudio) en períodos anteriores y 3 en el actual: En los 2 primeros períodos los objetivos eran los siguientes: objetivo1: desarrollo de las regiones menos favorecidas (PIB inferior al 75\% de la media comunitaria), objetivo 2: reconversión de las regiones afectadas por el declive industrial, objetivo 3: lucha contra en paro de larga duración e inserción de los jóvenes en el mercado laboral, objetivo 4: adaptación de los trabajadores a los cambios industriales y a los nuevos sistemas de producción. Objetivo 5 (5a y 5b) desarrollo rural y objetivo 6: regiones de baja densidad de población. Los objetivos $1,2,5$ b y 6 tienen un carácter específicamente regional y los objetivos 3,4 y 5a, sin embargo, un carácter 
TABLA 2. GASTOS PRESUPUESTARIOS: G. ESTRUCTURALES período 1995-2006 En millones de euros

\begin{tabular}{|c|c|c|c|c|c|c|c|c|c|c|c|c|}
\hline Año & 1995 & 1996 & 1997 & 1998 & 1999 & 2000 & 2001 & 2002 & 2003 & 2004 & 2005 & 2006 \\
\hline A) Total * & 80.9 & 83.6 & 86.1 & 89.2 & 92.5 & & & & & & & \\
\hline E) Total & & & & & 97.8 & 97.5 & 99.8 & 105.1 & 107.1 & 109.5 & 112 & 114.5 \\
\hline \begin{tabular}{|l|} 
B) \\
Acc.Est*
\end{tabular} & 26.3 & 27.7 & 29.4 & 31.2 & 32.9 & & & & & & & \\
\hline F) Act..est & cturales & ** & & & 36.1 & 35.2 & 36 & 38.8 & 39.8 & 40.7 & 41.7 & 42.8 \\
\hline \begin{tabular}{l|} 
C) \\
Fondos \\
Estruc. ${ }^{*}$ \\
\end{tabular} & 24.1 & 25.2 & 26.6 & 28.3 & 30.2 & & & & & & & \\
\hline G) Fondos & structura & es ${ }^{\star \star}$ & & & 31.4 & 31.3 & 32.1 & 31.3 & 30.3 & 29.2 & 28.2 & 27.3 \\
\hline $\begin{array}{l}\text { D) } \\
\text { Fondo } \\
\text { cohesión } \\
\star\end{array}$ & 2.1 & 2.3 & 2.6 & 2.7 & 2.7 & & & & & & & \\
\hline H)Fondos & cohesió & $n$ ** & & & 2.9 & 2.9 & 2.9 & 2.9 & 2.9 & 2.9 & 2.9 & 2.9 \\
\hline 1) Préstame & adhesión & $\star \star$ & & & & 1.0 & 1.0 & 1.0 & 1.0 & 1.0 & 1.0 & 1.0 \\
\hline J) Nuevos & stados $\mathrm{Mi}$ & embros $\star \star$ & & & & & & 3.6 & 5.6 & 7.6 & 9.6 & 11.6 \\
\hline$B / A$ & $0: 3251$ & 0.3313 & 0.3415 & 0.3498 & 0.3557 & 0.361 & 0.3607 & 0.3692 & 0.3716 & 0.3717 & 0.3723 & 0.3738 \\
\hline $\mathrm{C} / \mathrm{A}$ & 0.2979 & 0.3014 & 0.3089 & 0.3173 & 0.3265 & 0.321 & 0.3216 & 0.2978 & 0.2829 & 0.2667 & 0.2518 & 0.2384 \\
\hline $\mathrm{D} / \mathrm{A} / / \mathrm{H} / \mathrm{A}$ & 0.026 & 0.0275 & 0.0302 & 0.0303 & 0.0292 & $\begin{array}{r}0.029 \\
7 \\
\end{array}$ & 0.0291 & 0.0276 & 0.0271 & 0.0265 & 0.0259 & 0.0253 \\
\hline $\mathrm{G} / \mathrm{E}$ & & & & & 0.3211 & & & & & & & \\
\hline $\mathrm{H} / \mathrm{E}$ & & & & & 0.0297 & & & & & & & \\
\hline F/E & & & & & 0.3691 & & & & & & & \\
\hline
\end{tabular}

Source: Commission Européenne - Paquet Delors Il, Agenda 2000.

*: 1995-1999 A, B, C, D: prix 95 **: 1999-2006: E, F, G, H, I, J:

Prix97. 
no espacial y por lo tanto de índole general. En cada objetivo intervenían uno o varios fondos tal y como recogemos a continuación.

\begin{tabular}{|c|c|c|c|c|}
\hline OBJETIVOS & FEDER & FSE & FEOGA-0 & IFOP \\
\hline Objetivo1 & ${ }^{\star \star \star \star \star \star ~}$ & 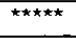 & 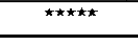 & 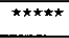 \\
\hline Objetivo2 & $\star \star \star \star * * * *$ & $\overline{\star \star \star \star \star \star \star}$ & & \\
\hline Objetivo3 & & 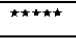 & & \\
\hline Objetivo4 & & $\star \star \star \star \star \star$ & & \\
\hline Objetivo5a & & & 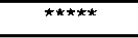 & 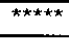 \\
\hline Objetivo5b & & & 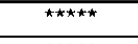 & \\
\hline Objetivo6 & 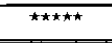 & 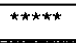 & 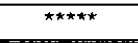 & \\
\hline
\end{tabular}

En el período actual existen novedades, que podemos resumir en relación al principio de la concentración en la disminución del número de objetivos, éstos pasan de ser cuatro objetivos territorializables y tres no territorializables a un total de tres: dos territorializables y uno no territorializable.

El nuevo objetivo 1 es un objetivo territorializable que cuenta con financiación de todos los fondos estructurales, incluido el IFOP que, en este período, adquiere el rango de Fondo estructural. Las regiones (NUTS II) objetivo 1, serán aquellas cuyo PIB per cápita sea inferior al $75 \%$ de la media comunitaria, igualmente se incluyen las regiones ultraperiféricas y las zonas que durante el período de programación anterior estaban cubiertas por el objetivo 6. Este mismo objetivo dará cobertura transitoriamente, a las regiones que en este período dejan de pertenecer al objetivo 1 . Aquellas que pasen a ser regiones objetivo 2 contarán con apoyo del FEDER hasta el 2006, el resto sólo hasta el 2005 y en el 2006 su apoyo se limitará al procedente del FSE, del FEOGA-O y del IFOP. Igualmente la antigua iniciativa PEACE estará incluida en el actual objetivo 1.

El objetivo 2 comprende las zonas de dificultad estructural, afectadas por la reconversión de cuatro tipos distintos: a) el 10\% son zonas de reconversión industrial y de servicios, antiguo objetivo 2 , b) el $5 \%$ son zonas rurales, c) el $2 \%$ zonas urbanas y d) el $1 \%$ zonas dependientes de la pesca, afectará a un porcentaje no muy inferior al de las antiguas zonas objetivo 2 y 5 b. Su financiación correrá a cargo del FEDER y del FSE. Las zonas que dejen de ser objetivo 1 y no pasen a ser objetivo 2, se beneficiaran en el año 2006 de ayudas del FSE y del FEOGA-G. Los fondos que se destinen a zonas rurales no provendrán del FEOGA-O, sino del FEOGA-G. 
Por último el nuevo objetivo 3, reagrupará a los antiguos objetivos 3 y 4 y recibirá financiación únicamente del FSE, el objetivo 3 tendrá por prioridad la adaptación y modernización de las políticas y sistemas de educación, de formación y de empleo.

Al margen del principio de concentración como tal, pero afectado de la misma filosofía de reducir el número de prioridades, hemos de decir que el número de iniciativas comunitarias queda también sensiblemente reducido, pasa de 14 en el último período a 4, prácticamente una por fondo. INTERRREG III (FEDER), LEADER III( FEOGA-0), EQUAL (FSE) y la Iniciativa URBAN II (FEDER).

b) Principio de adicionalidad, este principio tiene por finalidad evitar que los fondos estructurales sirvan para sustituir a las ayudas nacionales, y por lo tanto lo que implica es que los esfuerzos nacionales y comunitarios van a sumarse actuando conjuntamente es decir, implica la suma de esfuerzos financieros a distintos niveles de la administración, las modificaciones respecto al mismo en el período actual son mínimas, centrándose básicamente en la limitación de la frecuencia de verificación a tres fechas o períodos concretos. Los tipos de financiación se mantienen con pequeñas variaciones limitativas a la baja para inversiones en infraestructuras que generen recetas.

c) Principio de cooperación, implica una estrecha concertación entre la Comisión y las autoridades competentes a nivel nacional, regional o local designadas por cada Estado miembro en las diversas fases de programación.

d) Principio de programación, se trata que para el período de tiempo establecido en cada reforma, el proceso de toma de decisiones se ha delegado a los niveles inferiores de gobierno, interviniendo sólo el nivel superior en los casos en que no pueda resolver o decidir el órgano inferior; la programación lleva emparejado todo un proceso de toma de decisiones. Por último, el principio de programación, sigue apoyado en el principio de subsidiariedad. Se mantienen las fórmulas de programación ya conocidas del Marco Comunitario de Apoyo, MCA y de los Documentos Únicos de Programación (DOCUP) en el caso de los objetivos principales y el de diseño desde las prioridades de la administración supranacional a la nacional para los objetivos de la Iniciativas comunitarias: La principal novedad que se presenta en este período para el caso 
español radica en el deseo de la Comisión de que los programas operativos sean plurifondos, como ya ocurría en otros países: Esto significaría que en vez de existir un PO FEDER, Objetivo 1, un PO, FSE y un PO FEOGAO para la misma región, existiría únicamente un programa operativo por región objetivo y este sería plurifondo.

En cuanto a las modalidades de intervención, básicamente la PCES a través de sus principales instrumentos: los fondos estructurales, canaliza las ayudas que provienen de los mismos bien por medio de los Marcos Comunitarios de Apoyo, en adelante MCA o los DOCUP para los objetivos principales, más del $90 \%$ de los recursos, bien por medio de las iniciativas Comunitarias, en adelante IICC (5,4\% de los recursos); La principal diferencia entre estas dos vías radica en que la iniciativa en el caso de los MCAs recae en última instancia en los estados miembros y sus particularidades y en el caso de las MCC la iniciativa parte de la Comisión y priman los intereses comunitarios.

La canalización de ayudas para los objetivos principales se realiza básicamente a través de los distintos MCA, conlleva todo un proceso de reparto de fondos que se inicia con su concentración en torno a unos objetivos prioritarios espaciales y no espaciales por países, posteriormente se procede al reparto por Fondos e Instituciones, y finalmente se realiza el reparto por regiones. El procedimiento comienza con la presentación por los diferentes Estados miembros a la Comisión de sus respectivos Planes de Desarrollo Regional (PDR Objetivo1) en los cuales se describe la situación de partida con sus correspondientes estrangulamientos y estrategias adecuadas en pro del desarrollo regional; también se incluye una valoración medioambiental y un cuadro financiero global con carácter indicativo en el que se realiza una previsión de los recursos nacionales, regionales y comunitarios para llevar a buen término el PDR presentado. La Comisión valora los planes y establece de común acuerdo con el Estado miembro en cuestión un marco comunitario de apoyo para las intervenciones en los estados miembros, en el MCA se indican los objetivos prioritarios para el desarro1lo, las formas de intervención y la duración y el plan indicativo de las intervenciones. La otra vía dentro de este tipo de objetivos es a través de los Documentos Únicos de Programación, básicamente utilizados para las zonas objetivo 2, en cuyo caso en vez de un PDR se recibe un proyecto de DOCUP que tras su negociación y programación se convertirá en definitivo.

Hasta un 5,4\% del resto de las ayudas procedentes de los fondos estructurales se canalizará a través de las verdadero instrumento de política regional comunitaria independiente de las políticas de desa- 
rrollo regional, pues la iniciativa parte de la Comisión, y por lo tanto estas orientaciones pueden diferir de las prioridades que para el desarrollo de sus regiones plantean los diferentes Estados miembros. En principio y justamente por esta razón las ayudas que procedan de las IICC tendrán una menor repercusión en el impulso de desarrollo regional a través del modelo de desarrollo endógeno cuyo principal instrumento son las ayudas canalizadas a través del MCA. Las prioridades comunitarias en el caso de la IICC son consustanciales con el objeto particular de las diferentes iniciativas existentes en cada período de estudio, de todos modos como nota común a todas ellas apuntamos que sus principales destinatarias son también las regiones objetivo 1. La IICC existentes en el período 1989-1993 fueron: RECHAR, ENVIREG, STRIDE, INTERREG, REGIS,REGEN, PRISMA, TELEMATICA, EUROFORM, NOW, HORIZON, RETEX, KONVER Y LEADER. En el período 1994-99, algunas desaparecen, otras se mantienen y aparecen algunas nuevas hasta configurar el nuevo elenco de IICC, cual es: INTERREG II, LEADER II, REGIS II, NOW, HORIZON, YOUTHSTAR, ADAPT, RECHAR, RESIDER, KONVER, RETEX, INTUSTRIA TEXTIL PORTUGUESA, PYME, URBAN, PESCA Y PEACE. En el período 2000-2006, se reducen a 4: INTERREG III y URBAN II con financiación del FEDER, LEADER II con financiación del FEOGA-O y EQUAL con financiación del FSE

El último dato importante a tener en cuenta radica en conocer los recursos financieros para el período actual de programación por país (tablas adjuntas). Al margen de estas cantidades, una novedad de este período, se encuentra en la nueva "reserva de resultados", el 4\% de los créditos previstos en cada reparto nacional se consignan en reserva al inicio del período, y la comisión los asignará la mitad de período, en concertación con cada estado miembro, a los programas con mejores resultados. En la tabla 3 se presenta un cuadro resumen del reparto indicativo por Estados Miembros para el período 2000-2006.

Gastos anuales previstos para el período 200-2006 (Meuros 1999)

\begin{tabular}{|l|l|l|l|l|l|l|l|}
\hline Años & 2000 & 2001 & 2002 & 2003 & 2004 & 2005 & 2006 \\
\hline Fondos & 29.430 & 28.840 & 28.250 & 27.670 & 27.080 & 27.080 & 26.660 \\
\hline
\end{tabular}


Reparto por tipo de intervención par el período 2000-2006

\begin{tabular}{|l|r|r|r|}
\hline & \multicolumn{1}{|c|}{ Meuros } & \% (de Fondos) & \multicolumn{2}{|c|}{$\begin{array}{l}\text { (reservas s. } \\
\text { Transitoria) }\end{array}$} \\
\hline Objetivo 1 & 135.900 & 69,70 & 4,3 \\
\hline Objetivo 2 & 22.500 & 11,50 & - \\
\hline Objetivo 3 & 24.050 & 12,30 & $-1,4$ \\
\hline Pesca (fuera Obj 1) & 1.110 & 0,50 & - \\
\hline IICC: & 10.440 & 5,35 & \\
INTERREG & 4.875 & & \\
EQUAL & 2.847 & & \\
LEADER & 2.020 & & \\
URBAN & 700 & & \\
\hline Acciones de & 1.000 & & \\
innovación y & & & \\
asistencia técnica & & & \\
\hline
\end{tabular}

Estudio específico en función de sus peculiaridades, beneficiarios y proyectos objeto merece el fondo de cohesión, al que nos referiremos de forma más específica, al estudiar los instrumentos financieros para la Cohesión económica y social. A pesar de los progresos realizados por los estados beneficiarios del Fondo de cohesión: España, Irlanda, Portugal y Grecia y de que todos, con la excepción de Grecia, se encuentran, en la actualidad, dentro de la zona euro, tras haber superado el examen de los criterios de convergencia, la supervivencia del Fondo de Cohesión para el período 2000-2006 no se cuestiona. El Fondo de cohesión financia proyectos de infraestructuras y medio ambiente en aquellos países cuyo PNB es inferior al $90 \%$ de la media comunitaria.

El nuevo reglamento 1264/99 también aporta ciertas modificaciones para este nuevo período: Las modificaciones más significativas se refieren a la posibilidad de que algún estado beneficiario tras la evaluación intermedia que se realice en el 2003 deje de cumplir los criterios de elegibilidad, y por lo tanto, deje de percibir financiación por esta vía. Si algún estado miembro deja de ser elegible los créditos que debían de habérsele atribuido (2004-2006) se deducirán del presupuesto global.

\begin{tabular}{|l|l|l|l|l|l|l|l|}
\hline Año & 2000 & 2001 & 2002 & 2003 & 2004 & 2005 & 2006 \\
\hline Cuantía & 2.615 & 2.615 & 2.615 & 2.615 & 2.515 & 2.515 & 2.510 \\
\hline
\end{tabular}

La otra novedad se refiere a la "condicionalidad macroeconómica", ya que ésta, durante este nuevo período, no estará relacionada con el cumplimiento de los criterios de convergencia, sino con el cumplimiento de las obligaciones derivadas de los pactos de estabilidad y convergencia, concretamente en lo relativo al criterio del déficit público excesivo. 
TABLA 3

Reparto Indicativo por Estado Miembro para el período 2000-2006

\begin{tabular}{|c|c|c|c|c|c|c|c|}
\hline $\begin{array}{c}\text { Estados } \\
\text { Miembros }\end{array}$ & Objetivo 1 & $\begin{array}{c}\text { S. Transitoria } \\
\text { (ex. Obj.1) }\end{array}$ & Objetivo 2 & $\begin{array}{c}\text { S.transitoria } \\
\text { (Ex.obj 2y 5b) }\end{array}$ & Objetivo 3 & $\begin{array}{l}\text { Inst. Pesca } \\
\text { (Fuera obj1) }\end{array}$ & Total \\
\hline Alemania & 19.229 & 729 & 2.984 & 526 & 4.581 & 107 & 28.156 \\
\hline Austria & 261 & 0 & 578 & 102 & 528 & 4 & 1.473 \\
\hline Bélgica & 0 & 625 & 368 & 65 & 737 & 34 & 1.829 \\
\hline Dinamarca & 0 & 0 & $15 \overline{6}$ & 27 & 365 & 197 & 745 \\
\hline España & 37.744 & 352 & 2.553 & 98 & 2.140 & 200 & 43.087 \\
\hline Finlandia & 913 & 0 & 459 & 30 & 403 & 31 & 1.836 \\
\hline Francia & 3.254 & 551 & 5.437 & 613 & 4.540 & 225 & 14.620 \\
\hline Grecia & 20.961 & 0 & 0 & 0 & 0 & 0 & 20.961 \\
\hline Holanda & 0 & 123 & 676 & 119 & 1.686 & 31 & 2635 \\
\hline Irlanda (1) & 1.315 & 1.773 & 0 & 0 & 0 & 0 & 3.088 \\
\hline Italia & 21.935 & 187 & 2.145 & 377 & 3.744 & 96 & 28.484 \\
\hline Luxemburgo & 0 & 0 & 34 & 6 & 38 & 0 & 78 \\
\hline Portugal & 16.124 & 2.905 & 0 & 0 & 0 & 0 & 19.029 \\
\hline R. Unido (1) & 5.085 & 1.166 & 3.989 & 706 & 4.568 & 121 & 15.635 \\
\hline Suecia (2) & 722 & 0 & 354 & 52 & 720 & 60 & 1.908 \\
\hline EUR 15 & 127.543 & 8.411 & 19.733 & 2.721 & 24.050 & 1.106 & 183.564 \\
\hline
\end{tabular}

(1) Comprende la IC PEACE (2000-2004). (2) Comprende el programa especial para las zonas costeras suecas. 
El reparto por países responde a unas bandas calculadas en función de la población, PNB per cápita, mejora de la prosperidad nacional y superficie. El resultado es: España 61-63,5\%; Grecia 16-18\%; Portugal $16-18 \%$ e Irlanda $2-6 \%$.

\section{C) La cohesión económica y social y sus instrumentos financieros}

Los instrumentos financieros con independencia de su finalidad última, pueden ser clasificados en presupuestarios y no presupuestarios, y por lo tanto vamos a adoptar esta primera clasificación inicial en atención a la inclusión o no inclusión de los mismos en el presupuesto general de la CE. Por lo tanto los Fondos Estructurales y el Fondo de Cohesión no son sino una parte muy significativa de los mismos.

\section{a) Los instrumentos financieros presupuestarios en la} política de cohesión económica y social europea

Se trata de ayudas que forman parte del presupuesto CE: la política de cohesión económica y social tiene una línea presupuestaria abierta a tal fin: la rúbrica 2. En dicha línea se recogen 3 instrumentos generales: Fondos estructurales, Fondo de Cohesión y Mecanismo Financiero Espacio Económico Europeo. Existen asimismo otras ayudas presupuestarias con finalidades complementarias, su principal finalidad no es de tipo redistributivo sino potenciador de la actividad financiera y del crecimiento.

1) Los Fondos Estructurales. Se trata de los instrumentos más importantes de la política regional europea, que canalizan la mayor parte de las ayudas europeas al desarrollo regional.

El Fondo Europeo de Desarrollo Regional-FEDER, nacido en 1975, núcleo de la política regional europea y destinado a contribuir a la corrección de los principales desequilibrios regionales dentro de la comunidad mediante una participación en el desarrollo y en el ajuste estructural de las regiones menos desarrolladas y en la reconversión de las regiones industriales en declive.

El Fondo Social Europeo. El FSE aunque nace en 1958, no forma parte de los fondos estructurales hasta la reforma de 1988, se ocupa de los aspectos sociales de la política de cohesión económica y social: la mejora de las posibilidades de empleo de los trabajadores, el aumento de su nivel de vida y la movilidad profesional y geográfica. 
El Fondo Europeo de Orientación y Garantía Agrícola -sección Orientación-, fue creado en 1962 y participa de la política de cohesión económica y social subvencionando los objetivos 1,5 a (excluida la pesca que recae en el IFOP) y $5 \mathrm{~b}$.

El IFOP, nuevo instrumento financiero de Orientación Pesquera, nace en 1994 y su función consiste en integrar todos los aspectos estructurales de la política común de la pesca.

Estos fondos se agruparán en su reparto en torno a unos objetivos prioritarios tal y como ya hemos explicado con anterioridad.

2) El Fondo de Cohesión fue creado por el art. 130D del Tratado de Maastricht, se trata de un nuevo instrumento de carácter espacial, pues afectará a aquellos Estados cuyo PNB sea inferior al 90\% de la media europea, se destinará a proyectos de infraestructura y medioambiente; se pretende neutralizar el efecto que el esfuerzo inversor en dos áreas consideradas prioritarias como las infraestructuras de transporte y la política de medioambiente tenga sobre el déficit público en estos países.

3) El Mecanismo Financiero del Espacio Económico Europeo. En julio de 1993 entró en vigor un Acuerdo para establecer una zona de Libre Comercio entre los Estados miembros de la UE, (en aquel entonces 12), y los Estados miembros de la EFTA crean el Espacio Económico Europeo EEE. Este acuerdo creaba un mecanismo financiero, dotado de unos fondos aportados por los 6 países mencionados, para apoyar vía subvención al tipo de interés de préstamo y/o vía donaciones, proyectos en los sectores de protección medioambiental tras la $4^{\mathrm{a}}$ ampliación la UE asumió el compromiso financiero de dichos Estados en el mecanismo financiero EEE.

\section{b) Los instrumentos financieros no presupuestarios en la política de cohesión económica y social europea}

Se trata de ayudas que no proceden del presupuesto CE y que se materializan bajo la forma de préstamos. Estas ayudas resultan insignificantes en cuantía si comparamos la misma con la de las acciones estructurales propiamente dichas, sin embargo, resultan complementarias y en algunas ocasiones imprescindibles, ya que sin su existencia la cofinanciación necesaria al efecto de recibir las ayudas europeas sería prácticamente imposible. Los instrumentos no presupuestarios que tienen finalidad estructural, son: las intervenciones del BEI, las ayudas CECA y el nuevo instrumento comunitario -NIC-, siendo el BEI realmente el 
de mayor alcance en atención no sólo a sus recursos y finalidad, sino en atención su ámbito general en cuanto a sus destinatarios.

1) El BEI. Se trata de la institución bancaria de la UE cuya principal misión (art. 198E TCE) es la de contribuir al desarrollo equilibrado y sin altibajos del mercado común en interés de la Comunidad, proyectos que pueden ser clasificados en: a) proyectos para el desarrollo de las regiones más atrasadas, b) proyectos de interés común a varios Estados que por su envergadura no pueden ser financiados en su totalidad por los mismos y c) proyectos para modernizar empresas o crear nuevas actividades necesarias para el progreso del Mercado Común. Las actuaciones del BEI territorialmente se pueden dividir en interiores y exteriores; el objeto de nuestro estudio actual son las actuaciones del primer tipo y en concreto su línea $\mathrm{N}^{\mathrm{o}} 1$ de prioridades, es decir el desarrollo de las regiones menos favorecidas o aquejadas de problemas de reconversión. Sus actuaciones en esta línea afectan a inversiones en materia de equipamientos de base, grandes infraestructuras, implantación de unidades de producción de todos los tamaños etc. Las otras líneas de actuación interna se refieren a proyectos de interés común en las líneas de infraestructuras europeas, medioambiente y mejora en la calidad de vida, diversificación del abastecimiento energético y mejora de la calidad de vida de los ciudadanos y por último, existe una línea estrechamente relacionada con el fortalecimiento de la competitividad, en particular a través de inversiones en PYMES.

2) Las intervenciones CECA. Proceden del presupuesto operativo CECA, pero las hemos incluido entre los instrumentos no presupuestarios por estar al margen del presupuesto general $\mathrm{CE}$. Se trata siguiendo la misma normativa antes citada de ayudas de readaptación, préstamos, bonificaciones de intereses o garantías de la Comunidad Europea del Carbón y del Acero, CECA que se refieren a la readaptación, investigación o reestructuración del sector carbón.

3) Nuevo Instrumento Comunitario NIC. Se trata de préstamos de la $\mathrm{CE}$ directamente relacionados con la cohesión económica y social y que se instrumentalizaron a través del NIC, nuevo Instrumento comunitario para la promoción de la inversión. Se trataba de la emisión de empréstitos que afectaban a la financiación de proyectos de inversión para conseguir una convergencia y una integración mayor; estos proyectos se encuadraron en los objetivos comunitarios en los sectores de industria, energía e infraestructura y en los últimos años no se han vuelto a utilizar. 


\section{D) Valoración de las ayudas estructurales en relación con el desarrollo regional europeo en los períodos 1989-93 y 1994-99}

Para poder valorar los resultados de una determinada política comunitaria tendremos que conocer en primer lugar la importancia que a dicha política se le otorga en el contexto global de prioridades comunitarias, para ello vamos a analizar el peso relativo de los principales instrumentos financieros al servicio de dicha política. Una vez realizada esta primera aproximación, el segundo paso consiste en valorar si el destino específico de estas ayudas coincide con los estrangulamientos y potencialidades de las regiones europeas, de modo que tomando como punto de referencia el modelo de desarrollo endógeno, podamos predecir su adecuación al modelo de desarrollo elegido y la consecución de mejores niveles de convergencia real, en definitiva, constatar que los objetivos iniciales van cumpliéndose en el horizonte temporal previsto. El tercer paso consistiría en realizar una medición de resultados (impacto macroeconómico) mediante técnicas cuantitativas, nosotros nos limitaremos a comentar alguno de los resultados que estos modelos ofrecen, pero centraremos nuestras conclusiones básicamente en un estudio más bien analítico sobre la adecuación de los fondos a sus objetivos y al desarrollo del modelo de desarrollo endógeno. La falta de un estudio más detallado sobre el impacto macroeconómico se debe a la poca fiabilidad que nos suscitan los resultados obtenidos a través de modelos econométricos debido fundamentalmente a dos hechos: la imposibilidad de aislar en los mismos la influencia de los Fondos Estructurales y de Cohesión de otros factores que también inciden en la evolución de los indicadores económicos y la existencia de datos para un período temporal que resulta reducido en atención a los grados de libertad del modelo. 


\section{TABLA 4}

Reparto de fondos estructurales y de cohesión por países: 1989-93/1994-99 en meuros

\begin{tabular}{|c|c|c|c|c|c|c|}
\hline $\begin{array}{l}\text { ESTADO } \\
\text { MIEMBRO }\end{array}$ & $\begin{array}{c}\text { OBJ:1 } \\
\text { MCA } \\
\text { 1989-93, } \\
\text { (P.CO- } \\
\text { RRIENTES) }\end{array}$ & \begin{tabular}{|c|} 
TOTAL \\
1989-1993 \\
(P.CO- \\
RRIENTES)
\end{tabular} & $\begin{array}{c}\text { IICC } \\
\text { 1989-93 } \\
\text { MEUROS }\end{array}$ & $\begin{array}{c}\text { OBJ:1 MCA } \\
\text { 1994-1999 } \\
\text { (P. DE } \\
\text { 1994) }\end{array}$ & $\begin{array}{c}\text { TOTAL } \\
\text { 1994-1999 } \\
\text { (P. DE } \\
1994)\end{array}$ & $\begin{array}{c}\text { IICC 1994- } \\
99 \\
\text { MEUROS }\end{array}$ \\
\hline ALEMANIA & 2.955 & 6.431 & 415,9 & 13.640 & 21.729 & 2.211 \\
\hline BELGICA & 0 & 863 & 124 & 730 & 2.096 & 288 \\
\hline DINAMARCA & 0 & 430 & 28 & 0 & 844 & 102 \\
\hline ESPAÑA ${ }^{\star \star}$ & 10.171 & 15.087 & $1.128,9$ & 26.600 & 42.400 & 2.781 \\
\hline FRANCIA & 957 & 6.941 & 566 & 2.190 & 14.939 & 1.605 \\
\hline GRECIA & 7.528 & 9.161 & 711,5 & 13.980 & 17.736 & 1.154 \\
\hline HOLANDA & 0 & 813 & 88,9 & 150 & 2.616 & 422 \\
\hline IRLANDA ${ }^{\star \star}$ & 4.460 & 4.901 & 294,7 & 5.620 & 7.403 & 484 \\
\hline ITALIA & 8.504 & 11.872 & 667,4 & 14.860 & 21.651 & 1.897 \\
\hline LUXEMBURGO & 0 & 77 & 22,1 & 0 & 102 & 19 \\
\hline PORTUGAL ** & 8.451 & 9.460 & 724,4 & 13.980 & 17.629 & 1.061 \\
\hline REINO UNIDO & 793 & 5.329 & 512,8 & 2.360 & 12.918 & 1.573 \\
\hline AUSTRIA ${ }^{*}$ & & 71.365 & & 162 & 1.587 & 146 \\
\hline FINLANDIA* & & & & 0 & 1.659 & 149 \\
\hline SUECIA* & & & & 0 & 1.305 & 127 \\
\hline TOTAL & 43.818 & 71.364 & $5.284,7$ & 94.272 & 166.614 & 14.084 \\
\hline
\end{tabular}

* Período 1995-99 (P.1995) ***Fondo cohesión

Fuente: Elaboración propia con datos de la Comisión CE

TABLA 5

Fondo de cohesión

\begin{tabular}{|c|r|r|r|r|r|}
\hline PAÍS & ESPAÑA & PORTUGAL & GRECIA & IRLANDA & TOTAL \\
\hline ANO 1993 & 859 & 285 & 280 & 144 & 1.568 \\
\hline $\begin{array}{l}\text { PERIODO } \\
1994-99\end{array}$ & 7.950 & 2.601 & 2.602 & 1.301 & 14.454 \\
\hline
\end{tabular}

Fuente: Elaboración propia con datos de la Comisión CE Meuros. 


\section{TABLA 6}

Préstamos del BEI - objetivo 1

\begin{tabular}{|l|r|r|r|r|}
\hline & \multicolumn{3}{|c|}{ PERIOODO 1988-1993 } & \multicolumn{2}{r|}{ PERIOODO 1994-1999 } \\
\hline & Meuros & $\%$ total & Meuros & $\%$ Total \\
\hline Alemania & 2.303 & 8,51 & 5.400 & 19,75 \\
\hline Grecia & 1.463 & 5,40 & 2.368 & 8,66 \\
\hline España & 6.425 & 23,73 & 9.000 & 32,92 \\
\hline Francia & 2.219 & 8,20 & 150 & 0,55 \\
\hline Irlanda & 1.333 & 4,92 & 1.800 & 6,58 \\
\hline Italia & 8.053 & 29,74 & 1.732 & 6,34 \\
\hline Portugal & 5.123 & 18,92 & 6.100 & 22,31 \\
\hline R. Unido & 157 & 0,58 & 550 & 2,01 \\
\hline Bélgica & & & 239 & 0,87 \\
\hline TOTAL & 27.076 & 100,00 & 27.339 & 100 \\
\hline
\end{tabular}

* hasta marzo de 1997.

Meuros.

Una primera valoración de la importancia del problema del desarrollo regional en el contexto de la UE y de los recursos asignados a la PCES como política encargada de conseguir dicho objetivo económico, resulta positiva ya que la tendencia de las ayudas ha sido creciente, en el momento actual representan el $37 \%$ del gasto presupuestario. Del análisis conjunto de los datos relativos a los fondos estructurales y fondo de cohesión, canalizados vía MCA junto con los fondos estructurales canalizados vía IICC (Tabla 3), y los resultados del BEI para los períodos 1988-93 y 1994-99 (Tabla 5), se desprende que el volumen de estas ayudas se ha duplicado, tal y como se planteaba en la segunda reforma de la PCES, acercándose las dotaciones de la PCES a las de la PAC poco a poco; podemos asimismo concluir que las ayudas BEI resultan beneficiar en mayor medida a los Estados con NUTS II objetivo 1, de donde podemos deducir que las ayudas BEI pueden colaborar en la cofinanciación de las actuaciones con ayuda de los fondos estructurales, cuando las administraciones cofinanciadoras tengan problemas de liquidez, al coincidir las actuaciones programadas con la tipología de proyectos beneficiarios del BEI. Otra de las conclusiones positivas se refiere al cumplimiento de los principios de la PCES, la concentración de las ayudas en torno a los objetivos espaciales y no espaciales ha sido una realidad, y dentro del principio de concentración la prioridad del objetivo 1 como principal foco de desigualdades regionales la nota más característica (Tabla 3). Los Estados miembros con PIB/hab. más bajo, coinciden con aquellos con un número de NUTS II objetivo 1 mayor y resultan ser 
los Estados más beneficiados por la ayudas europeas en términos absolutos, una representación gráfica de la concentración de las ayuda estructural en la Comunidad por Estados miembros aportaría como resultados una mejor distribución de fondos estructurales para los países con menores niveles de PIB/hab. a medida que avanzan los años (Comisión Europea, 1997); se observa por lo tanto que existe una relación inversa entre el PIB/hab. y la distribución de los recursos comunitarios que parece de acuerdo con el criterio redistributivo que debe guiar el reparto de estos fondos. Si analizamos los resultados en términos relativos ECUS/ hab. los resultados no son tan espectaculares sobretodo en el caso español que pasa de ocupar el primer lugar al $5^{\circ}$, situándose Reino Unido en segundo lugar (Tabla 6). Un análisis de la tabla 3 relativa a las II.CC. completada con los resultados en el caso español nos conduciría a establecer la existencia de una relación positiva entre las regiones objetivo 1 y las ayudas que a dichos Estados llegan de la UE a través de la II.CC., sin embargo y a la vista de los resultados desagregados a nivel nacional, debemos añadir que esta segunda vía: la IC resulta ser menos eficaz para la disminución de las disparidades, debido a su reducida dotación. El Fondo de Cohesión (tabla 4) tampoco se revela como instrumento clave en la Política de cohesión económica y social, pues en el caso Español, la CC.AA. más beneficiada resulta ser Cataluña, región objetivo II y con unos indicadores económicos más saneados que los de otras regiones como es el caso de Castilla y León, receptora de menos fondos por dicho concepto (García Villarejo A. y Vega Mocoroa I., 1998) (de forma inversa al $\mathrm{PIB}$ )

El segundo punto de valoración es la adecuación al modelo de desarrollo endógeno. Del análisis de los principales instrumentos financieros al servicio de la PCES (fondos estructurales, fondos de cohesión y $\mathrm{BEI}$ ) y las prioridades o medidas en que se materializan sus ayudas, observamos que éstas se adecuan al modelo de desarrollo endógeno al estimular una mejor utilización del potencial endógeno de las regiones; las actividades más favorecidas corresponden a infraestructuras de comunicaciones en general y a aquellas infraestructuras de apoyo a la actividad económica y desarrollo del tejido industrial, así como a la formación del capital humano, prioridades, todas ellas de importancia en el modelo adoptado. El destino de las ayudas nos conduce a pensar que se está llevando una estrategia adecuada para luchar contra los estrangulamientos de las regiones menos desarrolladas, potenciando aquellas actuaciones que conduzcan a dichas regiones a un crecimiento mayor y a la consecución de niveles de renta más desarrollados; 
sirva como ej. el caso de Castilla y León que en el último período 199398 ha experimentado un crecimiento de 4 puntos y por lo tanto superior a la media europea. Los gastos en Inversión son los únicos que a medio plazo conducen por el buen camino al desarrollo regional en Europa, los gastos en consumo no tienen los mismos efectos, es por ello que la UE ha optado por una política de gastos y no de ingresos para la consecución del objetivo de la redistribución de la renta y de la consecución de la convergencia real en la Unión.

\section{TABLA 7}

\begin{tabular}{|c|c|c|c|c|c|c|}
\hline $\begin{array}{l}\text { ESTADO } \\
\text { MIEMBRO }\end{array}$ & $\begin{array}{c}\text { POBLACIÓN } \\
1995 \\
(1000) \\
\end{array}$ & \begin{tabular}{|c} 
DESEMPLEO \\
$1995-97$
\end{tabular} & $\begin{array}{c}\text { PIB/HAB } \\
1995 \\
\text { MEUROS }\end{array}$ & $\begin{array}{l}\text { PIB } 1995 \\
\text { MEUROS }\end{array}$ & $\%$ & $\begin{array}{c}\text { ECUS/HAB } \\
(1994-99) \\
\text { FONDOS }\end{array}$ \\
\hline ALEMANIA & 81.662 & 9,0 & 22.610 & 1.846 .351 & 30,79 & 534 \\
\hline BÉLGICA & 10.137 & 9,3 & 20.613 & 208.954 & 3,48 & 367 \\
\hline DINAMARCA & 5.228 & 6,8 & 24.747 & 129.378 & 2,16 & 216 \\
\hline ESPAÑA ${ }^{\star \star}$ & 39.210 & 22,2 & 10.989 & 430.877 & 7,18 & 893 \\
\hline FRANCIA & 58.138 & 11,8 & 20.109 & 1.169 .074 & 19,49 & 305 \\
\hline GRECIA ${ }^{* *}$ & 10.454 & 9,4 & 8.395 & 87.760 & 1,46 & 1.369 \\
\hline HOLANDA & 15.460 & 6,1 & 19.673 & 304.148 & 5,07 & 263 \\
\hline IRLANDA $^{\star \star}$ & 3.582 & 11,4 & 13.780 & 49.360 & 0,82 & 1.604 \\
\hline ITALIA & 58.350 & 12,1 & 14.249 & 831.409 & 13,86 & 534 \\
\hline LUXEMBURGO & 410 & 2,8 & 32.249 & 13.222 & 0,22 & 131 \\
\hline PORTUGAL ** & 9.916 & 7,1 & 8.068 & 80.000 & 1,33 & 1.417 \\
\hline REINO UNIDO & 58.606 & 8,0 & 14.442 & 846.411 & 14,11 & 1.573 \\
\hline AUSTRIA ${ }^{\star}$ & 3.358 & 4,3 & 22.006 & 177.081 & 2,95 & 210 \\
\hline FINLANDIA* & 5.108 & 15,7 & 18.857 & 96.323 & 1,61 & 301 \\
\hline SUECIA $^{*}$ & 8.827 & 9,5 & 20.116 & 177.560 & 2,96 & 248 \\
\hline TOTAL & 373.135 & 10,7 & 17.280 & 5.996 .944 & 100,00 & 628 \\
\hline
\end{tabular}

*Período 1995-99 (P.1995) **Fondo cohesión

Fuente: Elaboración propia con datos de la CE y del $\mathrm{M}^{\circ}$ de Economía y Hacienda.

En relación con el tercer punto de valoración respecto a la medición del impacto macroeconómico de la PCES hemos de indicar que con las limitaciones anteriormente expuestas, las estimaciones realizadas a partir del modelo MOISEES para el caso español (Cordero G., 1997) permiten concluir que en los períodos relativos a las dos reformas de la política regional, se estima que el crecimiento hubiera sido casi un $1 \%$ inferior, el empleo entre un 0,4 y un $0,5 \%$ inferior y la creación bruta de capital entre un 3,2 y un 4,7 inferior. 
En una primera aproximación podemos apreciar que las acciones estructurales se adecuan a la finalidad para la cual se crearon, es decir contribuir a eliminar las disparidades regionales favoreciendo el desarrollo económico de las regiones menos desarrolladas en mayor medida de acuerdo con el modelo de desarrollo endógeno.

Como ya apuntamos anteriormente en la $3^{\text {a }}$ Reforma de los fondos para el período 2000-2006, las líneas generales de la PCES se mantienen sin alteraciones sustanciales en lo relativo al modelo de desarrollo elegido y a sus prioridades. Sin embargo, al margen de otras cuestiones tales como la ampliación a los países PECO y la consignación en las nuevas perspectivas financieras de partidas para la preadhesión y adhesión de países aspirantes a convertirse en miembros de la UE en un futuro inmediato, se han producido algunas reformas relativas a la concentración de los fondos; esta concentración se va a llevar a cabo a tres niveles: concentración temática, geográfica y financiera, siendo su manifestación más clara la reducción de objetivos de seis a tres y el número de iniciativas de catorce también a tres, una por fondo. Este hecho junto con la reserva de eficacia que será distribuida en función de los buenos o malos resultados sobre la gestión y ejecución de los diferentes Programas Operativos, pueden influir en los resultados que se esperan para los próximos años para conseguir la disminución de las disparidades regionales en la UE.

\section{Conclusiones}

En este capítulo hemos intentado dar una visión de conjunto sobre el objetivo del desarrollo económico en la UE y sus instrumentos financieros, para ello hemos procedido a estudiar el tema desde dos enfoques distintos de desarrollo: el desarrollo exterior o lo que podríamos identificar como la política europea de cooperación al desarrollo externo, y el enfoque interno de desarrollo regional en el UE a través de la Política de cohesión económica y social. Mientras que la primera política descrita y sus instrumentos tienen un peso moderado en la UE y no plantea grandes reformas desde su inicio, la segunda ha ido adquiriendo gran importancia en los últimos años, al constatarse que el aumento de socios en la UE incrementa las disparidades regionales, poniendo en peligro los objetivos generales de la UE y la convergencia real en la misma; esto ha impulsando reformas tanto el modelo de desarrollo elegido como en los instrumentos financieros. 
En ambos enfoques de desarrollo, a pesar de contar con el presupuesto comunitario como instrumento financiero que canaliza el reparto de los fondos, el BEI se erige como un instrumento complementario clave en pro objetivo del desarrollo sea cual sea el enfoque en estudio; sin inversión no podemos hablar de desarrollo y el BEI tanto en sus acciones exteriores como interiores prioriza los proyectos de inversiones en infraestructuras. La Unión Europea se preocupa por el desarrollo económico tal y como demuestra su inclusión entre los objetivos generales de la UE art. 2 TCE. 


\section{Bibliografia \\ Isabel Vega Mocoroa \\ Las Políticas de Gasto Europeas y el Desarrollo Económico}

Ahijado M. (1998) La Unión Económica y' Monetaria Europea: mitos y realidades. Pirámide. Madrid.

AAVV (1998): Cap. VII y Cap. X. La Integración económica europea: curso básico. Lex Nova. Valladolid. (Vega Mocoroa, y García Villarejo y Vega Mocoroa).

Banco Europeo de Inversiones (1997) Informe anual 1996. Luxemburgo.

Barberán R. y Egea P. (1994) "Las políticas regional y social" cap. 2 en Economía de la Unión Europea. Cívitas. Madrid.

Bataller F. y Jordán J. (1994) "La dimensión exterior de la Unión Europea", cap. 7 en Economia de la Unión Europea. Cívitas. Madrid.

Cecchini P. (1988) Europa 1992: una apuesta de futuro. Alianza ed. Madrid.

Comisión Europea (1995) España: programas de desarrollo regional 1994.

Commission Européenne (1997) Limpact des politiques structurelles sur la cohésion économique et sociale de l'Union 1989-1999.

Commission Européenne (1997) Primer informe sobre la cohesión económica y social 1996.

Commision Europea. (1998) Vademecum presupuestario. SEC(98) 1100.

Commision Europea. (1997) "AGENDA 2000. Por una Unión más fuerte y más amplia". Boletín de la Unión Europea. Suplemento $5 / 97$.

Cordero Mestaza G. (1997) "Los Fondos para la cohesión en la Unión Europea: balance de una década y perspectivas". Cuadernos de Información Económica $\mathrm{N}^{\circ} 127$.
García Villarejo A., Vega Mocoroa I., García Ortega C. (1995) Las ayudas Europeas a Castilla y León para la cohesión económica y social. Junta de Castilla y León. Zamora.

Maillet P., \& Rollet P. (1987) Integration Economique Européenne. Nathan Superieur. Economie. Poitiers.

Molle W. \& Capellin R. (1988) Regional impact of comunity policies in Europe. ed Evebury. Aldershot.

Molle W. (1990) The Economics of European Integration: theory, practice, policy. Darmouth. Hampshire.

Padua Shiumpa T. (1985) Eficacia, estabilidad, equidad: Una estrategia para la evolución del sistema económico de las comunidades europeas. Alianza ed. Madrid.

Prud'homme R. (1993) "The potential role of the EC budget in the reduction of spatial disparities in a european economic and monetary union" in the Economics of Community Public Finance. European Economy' N $^{\circ}$ 5. 1993. CE.

Strasser D. (1993) La Hacienda de Europa. Instituto de Estudios Fiscales. Madrid.

Vega Mocoroa I. (1997) "La financiación de la UE: análisis de resultados y principales retos". En: Financiación y política presupuestaria de la UE. Lex Nova. Valladolid.

Vega Mocoroa I. (1997) Banco Europeo de Inversiones. Diccionario de Términos $\mathrm{Co}$ munitarios. Mc. Graw-Hill.

Vega Mocoroa X. (1998) "Les finances publiques européenes et leurs instruments pour l'objectif économique de la redistribution". Revue du MARCHÉ UNIQUE européen. Paris.

Yvars B. (1997) Économie européenne. Dalloz. Paris. 